\title{
Population health and Mediterranean diet in southern Mediterranean countries
}

\author{
Rekia Belahsen* and Mohamed Rguibi \\ Training and Research Unit on Food Sciences, Laboratory of Physiology Applied to Nutrition and feeding, School of \\ Sciences, Chouaib Doukkali University, El jadida, 24000, Morocco
}

Submitted 25 April 2006: Accepted 26 October 2006

\begin{abstract}
Background and objectives: In recent decades, the prevalence of non-communicable diseases (NCDs), such as obesity, diabetes and cardiovascular disorders has increased worldwide; the objective here is to describe the situation in southern Mediterranean countries.

Results: Data derived from surveys in the region countries showed that in 2002 more than $60 \%$ of all deaths in the southern Mediterranean region are attributed to NCDs. Cardiovascular diseases (CVD) caused from about 34.3 to $52 \%$ of all deaths, making it the major killer among NCDs. In almost all of the southern Mediterranean countries, CVD risk factors increased with age, affected more women and urban area and were significantly associated with obesity. The Mediterranean dietary pattern, generally recognised, as a healthy diet is still the model for southern Mediterranean population; however, following the rapid process of urbanisation, southern Mediterranean populations have changed their lifestyle and food habits and tend to shift from traditional food habit. Indeed, intake trends illustrate the fall in whole-grain intake with a rise in animal sources and vegetable oils. Dietary energy has been steadily increasing by approximately $1000 \mathrm{kcal}$ per capita per day between 1965 and 2000, exceeding per caput energy requirements. Protein and carbohydrate contribution to the energy intake show only small deviations and fat contribution to the energy intake is low, whereas fibre intake is generally low and that of SFA is high. Also, sedentarity appears to play a critical role in the development of body fat and may be a risk indicator for features of metabolic syndrome.

Conclusion: The major goal to prevent CVD should begin by preventing obesity through physical exercise and healthy nutrition. The nutritional prevention policy required should encourage population to adhere to the Mediterranean model.
\end{abstract}

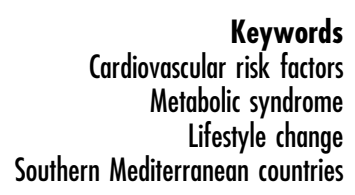

While the control and prevention of under-nutrition is an unfinished work, nutrition-related chronic diseases are increasing leading to disabilities and death globally and in developing countries, including Mediterranean countries, what is called nutrition transition.

The population of the countries in the south and east of the Mediterranean basin, currently around 400 million, will contribute almost two-thirds of the total Mediterranean basin population in 2025 . The majority of this population belong to developing and middle-income countries, where rapid change in patterns of diseases is evident and now accepted by WHO and national governments. Indeed, there is increasing evidence that certain lifestyles can lead to the onset of cardiovascular disease (CVD). These factors are smoking ${ }^{1}$, lack of physical activity ${ }^{2}$, $\operatorname{diet}^{3,4}$, hypertension ${ }^{5}$, hypercholesterolaemia ${ }^{6}$, glucose intolerance $^{7}$ and obesity 8,9 . Data derived mainly from high-income countries show that obesity increases the risk of CVD and diabetes. Although most of the global burden of CVD is in developing countries, few data are available in southern Mediterranean countries' populations ${ }^{10}$. The metabolic syndrome (Mets) mainly due to the simultaneous clustering of some metabolic abnormalities (such as diabetes, hyperlipaemia, obesity and hypertension) occurring in the same individual is of clinical importance thought to predict the future risk of all causes of mortality and CVD, and predictive of newly onset diabetes ${ }^{11}$. Estimates of the (Mets) prevalence vary because of the variability of evaluated populations and of diagnosis criteria $^{12}$. The determinants and aetiology of metabolic syndrome are not well understood and only few studies shed light on its development in southern Mediterranean countries ${ }^{13,14}$.

Dietary patterns, such as fibre, protein and fat intake are also presumably related to cardiovascular risks ${ }^{15}$. Also, Mediterranean-style diet is thought to be effective in 
reducing the prevalence of Mets and its associated cardiovascular risk and, the rate of all-causes and cause-specific mortality ${ }^{16,17}$. The paper examines health situation and Mediterranean dietary pattern in southern Mediterranean countries.

\section{Demographic profile of southern Mediterranean region}

The total population of southern Mediterranean countries has increased more than tripled from 1965 to 2000 and the percentage of people living in urban centres has dramatically increased in the same time period ${ }^{18}$. It is known that in these countries, being a poor urban dweller is worse than being a rural citizen. In the year 2001, there are countries (Egypt, Algeria and Morocco) with populations of more than 30 million inhabitants and other (Tunisia, Libya and Jordan) with less than 10 million populations. The annual average population growth rate was between 1.1 and 2.9\% during 2000-2005. There is country variation in urbanisation levels. While in Libya and Jordan $80 \%$ of the population live in urban areas, in Egypt the percentage of urban population is $48 \%$. Also, life expectancy at birth improved during the last years, it has increased by 10 years in the region during the past 30 years ${ }^{19-22}$; however, it still varies widely from 68.3 years in Egypt to 73 years in Libya and Tunisia. Infant mortality rates have also fallen most dramatically between 1970 and 1999. In 2003, infant mortality rates varied between 24.4/1000 live births in Libya and 36.6 live births in Morocco. This dramatic increase in life expectancy at birth and the decline in infant mortality rates demonstrate the general improvement in the quality of life in the region.

\section{Burden of CVD in southern Mediterranean countries}

The changes in the economic, social and demographic determinants of health and the adoption of unhealthy lifestyles are contributing to observed conversion in the disease pattern characterised by a progressive and accelerated rise in CVD in southern Mediterranean region.

In Libya, a survey carried out in 1998/1999 reported that diabetes is emerging as an important public health problem with a prevalence slightly higher in urban than in rural areas (14.5 vs. $13.5 \%$ ). The prevalence of newly diagnosed diabetes and that of known diabetes were 3.6 and $10.9 \%$ in urban and, 7.3 and $6.3 \%$ in rural areas, respectively. Associated risk factors with diabetes and glucose tolerance were age, family history of diabetes, hypertension, BMI, WHR and hypercholesterolaemia ${ }^{23}$.

In Tunisia, a household epidemiologic survey on a representative sample of the adult urban population of Soussa $(n=957)$ showed a high prevalence of hypertension ( $>160 / 95 \mathrm{mmHg}$ ): 18.8\% (adjusted rate: 15.6\%), history of diabetes $10.2 \%$, obesity (BMI > 30) $27.7 \%$ (with a higher prevalence in women (34.4\%)) and android obesity $36 \%{ }^{24}$. In 2001, results of a study population that was made up of 1837 people aged between 40 and 69 years show that $38.7 \%$ of men and $48.2 \%$ of women were hypertensive ( $\geq$ SBP $140 \mathrm{mmHg}$ and/or DBP $90 \mathrm{mmHg}$ or on antihypertensive medication), $15.7 \%$ of men and $14.9 \%$ of women were diabetic ${ }^{20}$.

In Algeria, the first detailed prevalence data in an Algerian population reported in a study ${ }^{25}$ involving a representative sample of 1457 subjects aged 30-64 years from Setif Wilaya, showed that the prevalence of type 2 diabetes and glucose intolerance has an important socioeconomical impact. The prevalence of diabetes was $8.2 \%$ and increased with age. Also, 50\% of diabetes cases were undiagnosed, without any difference according to sex or urban (7.3\%) vs. rural (9.7\%) distribution. On the other hand, results from a pilot survey (2003) realised in Setif and Mostaganem show that $27.6 \%$ of population were hypertensive ( $\geq$ SBP $140 \mathrm{mmHg}$ and/or DBP $90 \mathrm{mmHg}$ ) and $6 \%$ were diabetic ${ }^{20}$.

In Morocco, the data on anthropometric status in children under 5 years of age show that both undernourishment and overweight are prevalent ${ }^{26,27}$. In adults, data from the 1984 national household consumption and expenditure survey show that in 1984, a prevalence of 9.8\% for underweight, $21.4 \%$ for overweight (16.9 and $25.5 \%$ men and women, respectively) and $4.1 \%$ for obesity (1.6 and $6.4 \%$ men and women, respectively) ${ }^{28}$. More recently, in the year 1998, these prevalence decreased for underweight (4.7\%) and increased for overweight (27.1\%) (21.1\% men vs. 29\% women) and obesity (11.7\%) (4.3\% men vs. 16\% women). The prevalence of CVD risk factors are also increased ${ }^{29}$. Indeed, a more recent national level survey carried out in 2000 on 1500 men and women aged $15-60$ years $^{30}$, indicated that the prevalence of obesity has doubled (17.8\%) among women, associated with diabetes (6.6\%), hypertension (33.6\%), hypercholesterolaemia (29\%) and CVD.

In Jordan, another southern Mediterranean country, the results from Jordan Population and Family Health Survey (2002) show that $26.3 \%$ of women aged between 15 and 49 years are obese, $22.2 \%$ were hypertensive and $6.4 \%$ were diabetic $^{20}$. The problem concerned also adolescent, as demonstrated by the global School-Based Student Health Survey data (2003) indicating 3.5\% of students aged 10-18 years are obese ( $\geq 95$ th percentile for age/sex group).

Similarly, different surveys in Egypt have concluded that the primary nutritional problem for many Egyptian adults is a tendency towards obesity. According to the results of Hassanyn (2000), there was an increase in mean BMI to reach $30 \pm 4 \mathrm{~kg} \mathrm{~m}^{-2}$ as well as an increase in the prevalence of obesity in mothers (42\%) (BMI $>30$ $\left.\mathrm{kg} \mathrm{m}^{-2}\right)^{31}$.

Being overweight is associated with a higher risk of CVD, type 2 diabetes, ischaemic heart disease, hypertension 
and cancers ${ }^{32}$. In almost all of the southern Mediterranean countries populations, CVD risk factors and metabolic syndrome increased with age, affected more women and urban area than men and rural area and were also associated with obesity (Table 1) ${ }^{14,33,34}$ that unfortunately reach epidemic proportions particularly among women (Table 2) ${ }^{20}$. Therefore, there is a need to intensify efforts in the region to strengthen programmes for the prevention and control of obesity.

It is predicted that chronic diseases will account for almost three-quarters of all deaths worldwide by the year 2020 , and that $71 \%$ of deaths due to ischaemic heart disease (IHD), $75 \%$ of deaths due to stroke and $70 \%$ of deaths due to diabetes will occur in developing countries $^{35}$. The number of people with diabetes will increase by more than 2.5-fold, from 84 million in 1995 to 228 million in 2025 in the developing world ${ }^{36}$. On a global basis, $60 \%$ of the burden of chronic diseases will occur in developing countries ${ }^{36}$. In 2002, more than $60 \%$ of all deaths in the southern Mediterranean region are attributed to non-communicable diseases (NCDs). In general, CVD caused about $34.3-52 \%$ of all deaths, making it the major killer among NCDs ${ }^{20}$. The most common NCDs, such as CVD, chronic obstructive pulmonary disease, diabetes mellitus and hypertension are linked by common preventable risk factors related to lifestyle. The most important are tobacco use, unhealthy diet and physical inactivity. The prevention of these diseases should therefore have a common focus of controlling these risk factors in an integrated manner.

\section{Sedentary lifestyle}

Sedentary behaviour is one of the main contributory factors to increased obesity rates and its cardiovascular risk factors. Indeed, a high percentage of the population have decreased physical activity at work and leisure by spending more hours per week watching TV and the utilisation of more vehicles and activity saving appliances $^{37}$. According to the results of Jordan Global SchoolBased Student Health Survey, $44.2 \%$ of males and $42.2 \%$ of females spent 3 or more hours sitting and $44.6 \%$ of males and $45.2 \%$ of women did not walk or bike ${ }^{20}$. Also, in Tunisia, about $15 \%$ of the population aged $18-69$ years are inactive ${ }^{20}$. Besides, a survey conducted in 2002 among Moroccan women aged over 15 years, on the association between physical inactivity and cardiovascular risk factors, indicated that physical inactivity appears to play a critical role in the development of body fat and may be a risk indicator for features of metabolic syndrome $^{13,38}$. Most of those women were involved in a traditional sedentary occupation and the time spent in the tradition of tea consumption and afternoon sleeping habits increased with the number of metabolic syndrome

Table 1 Prevalence of (Mets) components according to age, sex and area of residence in Tunisia and Morocco

\begin{tabular}{|c|c|c|c|c|c|c|}
\hline & Large waist \% (N) & High TG \% (N) & $\begin{array}{c}\text { High total } \\
\text { cholesterol \% (N) }\end{array}$ & $\begin{array}{l}\text { High blood } \\
\text { pressure \% (N) }\end{array}$ & $\begin{array}{l}\text { High glucose } \\
\%(N)\end{array}$ & $(\text { Mets })^{*} \%(\mathrm{~N})$ \\
\hline \multicolumn{7}{|l|}{ Morocco } \\
\hline Women ${ }^{23}$ & 24.2 & 6.1 & 5.7 & 25.1 & 8.2 & 8 \\
\hline Women $^{25}$ & 28.8 & 6.1 & 10.1 & 35.8 & 15 & 17.8 \\
\hline \multicolumn{7}{|l|}{ Tunisia $^{14}$} \\
\hline & \multirow{2}{*}{\multicolumn{6}{|c|}{ According to age }} \\
\hline Men & & & & & & \\
\hline $20-29$ & $7.5(175)$ & $11.9(183)$ & $8.8(183)$ & $31.3(201)$ & $6.1(188)$ & 2.8 (152) \\
\hline $30-39$ & $4.4(176)$ & 29.1 (236) & $21.9(236)$ & $28.9(261)$ & $4.8(252)$ & 7.7 (157) \\
\hline $40-49$ & $8.5(230)$ & 29.5 (249) & 27.7 (262) & 34.4 (283) & $17.7(271)$ & 16.5 (193) \\
\hline $50-59$ & $7.3(157)$ & 28.7 (156) & 30.6 (156) & $52.4(175)$ & $17.3(169)$ & 13.7 (127) \\
\hline $60-69$ & $13.0(214)$ & $17.2(200)$ & 26.9 (202) & 65.6 (227) & 25.4 (218) & $14.5(180)$ \\
\hline$\geq 70$ & $11.5(148)$ & $21.1(135)$ & 33.1 (136) & $76.1(155)$ & $23.3(149)$ & $28.0(123)$ \\
\hline \multicolumn{7}{|l|}{ Women } \\
\hline $20-29$ & $36.3(556)$ & $8.9(556)$ & $14.2(559)$ & $22.2(614)$ & $3.5(590)$ & $5.6(477)$ \\
\hline $30-39$ & $37.2(609)$ & $16.1(612)$ & 20.7 (813) & $29.5(658)$ & $7.3(641)$ & 7.7 (533) \\
\hline $40-49$ & $27.6(441)$ & $21.3(423)$ & 25.8 (423) & $45.5(471)$ & 16.4 (462) & $14.6(366)$ \\
\hline $50-59$ & $28.6(289)$ & $25.3(295)$ & $42.3(296)$ & $63.1(325)$ & $24.1(318)$ & $28.2(257)$ \\
\hline $60-69$ & $27.9(285)$ & $31.2(280)$ & $52.9(291)$ & 75.3 (321) & 33.8 (308) & $41.9(243)$ \\
\hline$\geq 70$ & $27.9(153)$ & $29.6(138)$ & $53.3(138)$ & $82.5(166)$ & 26.7 (163) & $39.5(119)$ \\
\hline & \multicolumn{6}{|c|}{ According to area of residence } \\
\hline Men & & & & & & \\
\hline Urban & $12.3(624)$ & $25.9(653)$ & $29.4(657)$ & $46.4(717)$ & $17.8(681)$ & $16.2(543)$ \\
\hline Rural & $3.1(476)$ & $18.7(506)$ & $14.9(507)$ & $43.3(585)$ & $10.5(566)$ & $8.2(389)$ \\
\hline \multicolumn{7}{|l|}{ Women } \\
\hline Urban & 40.0 (1397) & 22.1 (1403) & 33.6 (1407) & $46.3(1526)$ & $17.3(1484)$ & $21.5(1208)$ \\
\hline Rural & $19.0(936)$ & $14.9(911)$ & $21.9(913)$ & $41.1(1029)$ & 11.5 (998) & $10.6(787)$ \\
\hline
\end{tabular}

${ }^{*}$ (>3 metabolic components). 
Table 2 Trend of obesity (BMI $>30 \mathrm{~kg} \mathrm{~m}^{-2}$ ) in southern Mediterranean countries ${ }^{20}$

\begin{tabular}{lrrrrrrr}
\hline & \multicolumn{3}{c}{ Male } & & \multicolumn{3}{c}{ Female } \\
\cline { 2 - 4 } \cline { 7 - 8 } & 2002 & 2005 & 2010 & & 2002 & 2005 & 2010 \\
\hline Algeria & 4.52 & 5.18 & 6.44 & & 11.91 & 13.44 & 16.20 \\
Morocco & 3.67 & 3.67 & 3.67 & & 19.03 & 20.52 & 23.1 \\
Jordan & 19.62 & 19.62 & 19.62 & & 40.19 & 35.62 & 37.89 \\
Tunisia & 7.74 & 7.74 & 7.74 & & 28.78 & 30.20 & 32.57 \\
Egypt & 21.98 & 21.98 & 21.98 & & 39.34 & 45.46 & 48 \\
Libya & 10.74 & 11.45 & 12.67 & & 21.13 & 22.52 & 24.87 \\
\hline
\end{tabular}

components. On the contrary, women without metabolic syndrome components tended to expend more energy (walking activity) than those with metabolic syndrome $^{13,38}$. All of these data demonstrated the high level of sedentarity in the southern Mediterranean population.

\section{Dietary habit in southern Mediterranean countries}

The Mediterranean diet is considered the golden standard of healthy nutrition associated with decreased morbidity and mortality, especially from cardiovascular causes. On the other hand, studies on populations which have changed their dietary habits, switching to more westernised diet is suggested to be associated with increased prevalence of diet-related diseases. This could be probably the case in southern Mediterranean region. Analysis of FAOSTAT data ${ }^{18}$ shows a significant progress in raising food consumption per person over the past three decades. This growth in food available for consumption has been accompanied by some structural changes and a shift in diet away from barley towards wheat and more livestock products and vegetable oils. Dietary energy measured in kilocalories per capita per day has been steadily increasing by approximately $1000 \mathrm{kcal}$ per capita per day between 1965 and 2000 (Table 3), exceeding per caput energy requirements ${ }^{18}$. The important point is that there has been a remarkable increase in the intake of dietary fats over the past three decades in the region ${ }^{18}$. There are large variations in the contribution of total fats to the energy intake; the lowest contribution is recorded in Egypt (14.5\%), while the highest is recorded for Libya
(27\%). Also, Table 3 shows that the percentage of protein has remained constant while the percentage of carbohydrates tend to decrease (except for Egypt) over the 36year period.

When compared with Algeria, the contribution of fat to the energy intake was low in Egypt and Morocco, while that of carbohydrates was high (Fig. 1).

Despite deviations observed in dietary profile among southern Mediterranean countries, reflecting probably geographic, cultural and socio-economic variation, we can say that their diet profile is still comparable with the traditional Mediterranean pattern. Indeed, protein and carbohydrate contribution to the energy intake show small deviations while that of fat contribution, lower probably because of a low consumption of plant origin (Fig. 1), follow the recommendation. However, fibre intake is generally lower and that of saturated fatty acid (SFA) higher $^{34,39}$. Karamanos et al. (2002) study comparing two countries in the region showed that most subjects in Algeria and Egypt follow the recommendation concerning proteins but there are variations for fat and fibre. The proportion of subjects who meet the recommendation for all major nutrients, i.e. carbohydrates, fat and protein, was $12 \%$ in Algeria and $75.7 \%$ in Egypt and these percentages decreased to $41-45 \%$ for Egypt and 0-2.4\% for Algeria when fibres are included ${ }^{39}$. In fact, Egyptian population consumed more bread, cereals, legumes and vegetables and less fruits, meat and fat compared with Algerian population $^{39}$.

\section{Conclusion}

Southern Mediterranean countries are undergoing health and nutrition transition. Indeed, while malnutrition and micronutrients deficiencies are not eradicated there is an increased prevalence of NCDs. However, these NCDs are not recognised as a high public health priority in a majority of southern Mediterranean countries, as they are still confronted with the heavy burden of infectious diseases and poor maternal and child health. This health and nutrition transition is happening in the absence of steady and significant economic growth.

Data reported on this region showed that there is a shift in dietary habits from a traditional Mediterranean diet to

Table 3 Energy consumption (kcal per capita per day) and proteins, lipids and carbohydrates contribution to the energy intake in southern Mediterranean countries $^{18}$

\begin{tabular}{|c|c|c|c|c|c|c|c|c|}
\hline \multirow[b]{2}{*}{ Countries } & \multicolumn{2}{|c|}{ Energy } & \multicolumn{2}{|c|}{ Proteins \% } & \multicolumn{2}{|c|}{ Lipids \% } & \multicolumn{2}{|c|}{ Carbohydrates \% } \\
\hline & $1965 / 67$ & $2000 / 02$ & $1965 / 67$ & $2000 / 01$ & $1965 / 67$ & $2000 / 01$ & $1965 / 67$ & $2000 / 01$ \\
\hline Egypt & 2287 & 3318 & 11.6 & 11.4 & 15.9 & 14.5 & 72.5 & 74.2 \\
\hline Jordan & 2152 & 2824 & 10.6 & 10.8 & 18.7 & 25.1 & 70.7 & 64 \\
\hline Libya & 2061 & 3324 & 10 & 10 & 22 & 27 & 67 & 62 \\
\hline Tunisia & 2323 & 3272 & 11 & 11 & 23 & 25 & 67 & 63 \\
\hline Algeria & 1740 & 2990 & 11 & 11 & 16 & 20 & 73 & 69 \\
\hline
\end{tabular}




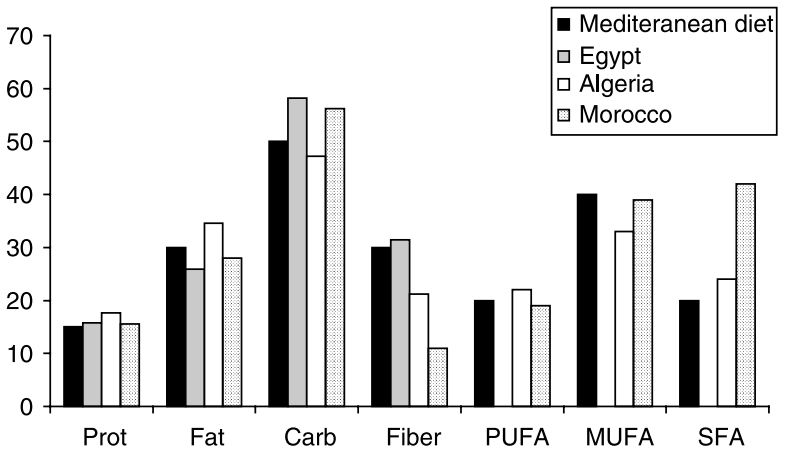

Fig. 1 Qualitative composition of the diet in Egypt, Algeria and Morocco compared to Mediterranean $\operatorname{diet}^{18,34}$

industrial food which could explain, in part, the nutritional and metabolic disorders reported in this region population. Unhealthy dietary practices include the high consumption of saturated fats and refined carbohydrates, low consumption of fibre as well as sedentary behaviour. Increased urbanisation was also accompanied by a progressive increase in cardiovascular risk factors, such as obesity, hypertension, diabetes and hypercholesterolaemia.

The global projections indicate that NCDs, particularly CVD, may reach epidemic proportions in developing countries in the next two decades. Therefore, there is a need to intensify efforts in the region to strengthen programs for the prevention and control of NCDs. The urgent need is to control obesity through a nutritional prevention policy by encouraging population to adhere to the Mediterranean dietary habit model and enhance their physical activity level.

\section{References}

1 A preliminary report from the Pathobiological Determinants of Atherosclerosis in Youth (PDAY) Research Group. Relationship of Atherosclerosis in young men to serum lipoprotein cholesterol concentrations and smoking. Journal of the American Medical Association 1990; 264: 3018-24.

2 Shaw LW. Effects of a prescribed supervised exercise program on mortality and cardiovascular morbidity in patients after myocardial infarction. The National Exercise and Heart Disease Project. American Journal of Cardiology 1981; 48: 39-46.

3 Bao W, Srinivasan SR, Wattigney WA, Berenson GS. The relation of parental cardiovascular disease to risk factors in children and young adults. The Bogalusa Heart Study. Circulation 1995; 91: 365-71.

4 Woo J, Ho SC, Chan SG, Sham A, Yuen YK, Masarei JL. Lipid profile in the Chinese old-old: comparison with younger age groups and relationship with some cardiovascular risk factors and presence of diseases. Cardiology 1993; 83: 407-14.

5 Kannel WB. Role of blood pressure in cardiovascular disease: the Framingham study. Angiology 1975; 26: 1-14.

6 Stamler J, Wentworth D, Neaton JD. Is relationship between serum cholesterol and risk of premature death from coronary heart disease continuous and graded? Findings in 356,222 primary screenees of the Multiple Risk Factor
Intervention Trial (MRFIT). Journal of the American Medical Association 1986; 256: 2823-8.

7 Fuller JH, Shipley MJ, Rose G, Jarrett RJ, Keen H. Coronaryheart-disease risk and impaired glucose tolerance. The Whitehall study. The Lancet 1980; 1(8183): 1373-6.

8 Jeffery RW, Wing RR, French SA. Weight cycling and cardiovascular risk factors in obese men and women. American Journal of Clinical Nutrition 1992; 55: 641-4.

9 Hubert HB, Feinleib M, McNamara PM, Castelli WP. Obesity as an independent risk factor for cardiovascular disease: a 26-year follow-up of participants in the Framingham Heart Study. Circulation 1983; 67: 968-77.

10 Yusuf S, Hawken S, Ounpuu S, Bautista L, Franzosi MG, Commerford P, Lang CC, Rumboldt Z, Onen CL, Lisheng L, Tanomsup S, Wangai P Jr, Razak F, Sharma AM, Anand SS. INTERHEART Study Investigators. Obesity and the risk of myocardial infarction in 27000 participants from 52 countries: a case-control study. The Lancet 2005; 366(5): 1640-9.

11 Ford ES. Risks for all-cause mortality, cardiovascular disease, and diabetes associated with the metabolic syndrome. Diabetes Care 2005; 28: 1769-78.

12 Eckel RH, Grundy SM, Zimmet PZ. The metabolic syndrome. The Lancet 2005; 365: 1415-28.

13 Rguibi M, Belahsen R. Metabolic syndrome among Moroccan Sahraoui adult women: its prevalence and characteristics. American Journal of Human Biology 2004; 16: 598-601.

14 Bouguerra R, Ben Salem L, Alberti H, Ben Rayana C, El Atti J, Blouza S, Gaigi S, Achour A, Ben Slama C, Zouari B. Prevalence of metabolic abnormalities in Tunisian adults: a population based study. Diabetes Metab 2006; 32(3): 215-21.

15 Hermansen K. Diet, blood pressure and hypertension. The British Journal of Nutrition 2000; 83: S113-9.

16 Knoops KT, de Groot LC, Kromhout D, Perrin AE, MoreirasVarela O, Menotti A, van Staveren WA. Mediterranean diet, lifestyle factors, and 10-year mortality in elderly European men and women: the HALE project. Journal of the American Medical Association 2004; 292(12): 1433-9.

17 Esposito K, Marfella R, Ciotola M, Di Palo C, Giugliano F, Giugliano G, D'Armiento M, D'Andrea F, Giugliano D. Effect of a Mediterranean-style diet on endothelial dysfunction and markers of vascular inflammation in the metabolic syndrome: a randomized trial. Journal of the American Medical Association 2004; 292(12): 1440-6.

18 FAO. Nutrition Country Profiles. http://www.fao.org/ag/ AGN/nutrition/profiles_by_country_fr

19 The works of WHO in the Estearn Mediterranean region. Annual report. Regional director, 1 January 31 December 2000. WHO EMRO 600, 2001.

20 WHO Global InfoBase. online. http://www.who.int/ncd_su rveillance/infobase/web/infobasepolicymaker/reports/reportlistcountries.aspx

21 Human Development Report 2002. United Nations Development Programe. New York: Oxford University Press, 2002.

22 Direction de Planification et des Ressources Financières, Service des Etudes et de l'Information Sanitaire. Ministère de la Santé. Santé en chiffres 2004.

23 Kadiki OA, Roaeid RB. Prevalence of diabetes mellitus and impaired glucose tolerance in Benghazi Libya. Diabetes Metabolism 2001; 27(6): 647-54.

24 Ghannem H, Fredj AH. Epidemiological transition and cardiovascular risk factors in Tunisia. Revue Epidemiologique de la Sante Publique 1997; 45(4): 286-92.

25 Malek R, Belateche F, Laouamri S, Hamdi-Cherif M, Touabti A, Bendib W, Nechadi A, Mekideche FZ, Hanat S. Prevalence of type 2 diabetes mellitus and glucose intolerance in the Setif area (Algeria). Diabetes Metabolism 2001; 27(2 Pt 1): $164-71$. 
26 Demographic and Health Survey (DHS) and Moroccan Ministry of Health. Enquête nationale sur la planification familiale, la fécondité et la santé de la population au Maroc. Rapport National (ENPS) 1987.

27 Demographic and Health Survey (DHS) and Moroccan Ministry of Health. Enquête nationale sur la planification familiale, la fécondité et la santé de la population au Maroc. Rapport National (ENPS II) 1992.

28 Direction de la statistique. Consommation et dépenses des ménages 1984/1985. Vols, 1, 5, 6 and 7. Rabat, Morocco, Statistics office, 1992.

29 Direction de la statistique. Enquête Nationale sur les Niveaux de Vie des Ménages 1998/99. Rabat, Morocco: Statistics office, 2000

30 Tazi MA, Abir-Khalil S, Chaouki N, Cherqaoui S, Lahmouz F, Srairi JE, et al. Prevalence of the main cardiovascular risk factors in Morocco: results of a national survey, 2000. Journal of Hypertension 2003; 21(5): 897-903.

31 Hassanyn AS. Food consumption pattern and nutrients intake among different population groups in Egypt. Final Report (part I), Nutrition Institute, Egypt, 2000 WHO/EMRO.

32 World Health Organisation. Obesity: Preventing and Managing the Global Epidemic. Working Group on Obesity. Geneva: World Health Organisation (WHO), 1998.

33 Belahsen R, Bermudez OI, Mziwira M, Fertat F, Newby PK, Tucker KL. Obesity and related metabolic disorders are prevalent in Moroccan women of child-bearing age. International Journal of Diabetes \& Metabolism 2005; 13(3): 159-66.
34 ElAyachi M, Mziwira m, lairon D, Belahsen R. Food Consumption in an Agricultural Community of Morocco: Comparison with the Traditional Mediterranean Diet. Proceeding of the 18th of International Congress of Nutrition, 19-23 September, 2005. ICC, Durban, South Africa. ISBN: 3-8055-8015-0.

35 World Health Organization. The world health report 1998. Life in the 21st Century: A Vision For All. Geneva: World Health Organization, 1998. ISBN 9241561890. ISSN 1020-3311: 1-237.

36 Report of a Joint WHO/FAO Expert Consultation. Diet, nutrition and the prevention of chronic diseases. WHO 2003 WHO Technical Report Series 916: 1-160.

37 Barry M, Popkin BM. The nutrition transition and its health implications in lower-income countries. Public Health Nutrition 1998; 1(1): 5-21.

38 Rguibi M, Belahsen R. Overweight and obesity among urban Sahraoui women of south Morocco. Ethnicity and Disease 2004; 14: 542-7.

39 Karamanos B, Thanopoulou1 A, Angelico2 F, Assaad-Khalil S, Barbato A, Del Ben M, Dimitrijevic-Sreckovic V, Djordjevic P, Gallotti C, Katsilambros N, Migdalis I, Mrabet M, Petkova M, Roussi1 D, Tenconi MT. Nutritional habits in the Mediterranean Basin. The macrontrient composition of diet and its relation with traditional Mediterranean diet. Multi-centre study of the Mediterranean Group for Study of Diabetes (MSGD). European Journal of Clinical Nutrition 2002; 56: 1-9. 